\title{
Concentrações plasmáticas e eritrocitárias de zinco em idosos portadores e não-portadores de catarata senil em um serviço oftalmológico especializado de Teresina-Piauí
}

\author{
Plasma and erythrocyte zinc concentrations in elderly patients with and \\ without senile cataract in a tertiary eye care center at Teresina-Piauí
}

Fábio Martins Soares ${ }^{1}$

Nadir do Nascimento Nogueira ${ }^{2}$

Dilina do Nascimento Marreiro ${ }^{3}$

Cecília Maria Resende Gonçalves de Carvalho ${ }^{4}$

Semiramis Jamil Hadad do Monte ${ }^{5}$

José Machado Moita Neto ${ }^{6}$

Viviane de Sousa Rocha ${ }^{7}$

Bárbara Verônica Sousa Cardoso ${ }^{8}$
Trabalho de Mestrado em Ciências e Saúde, Centro de Ciências da Saúde, Universidade Federal do Piauí UFPI - Teresina (PI) - Brasil.

Professor de Oftalmologia da Universidade Estadual do Piauí e pós-graduando, Nível Mestrado, pela Universidade Federal do Piauí - UFPI - Teresina (PI) - Brasil.

Professora-Associada do Departamento de Nutrição da UFPI - Teresina (PI) - Brasil.

Professora-Doutora do Departamento de Nutrição da UFPI - Teresina (PI) - Brasil.

${ }^{4}$ Professora-Doutora do Departamento de Nutrição da UFPI - Teresina (PI) - Brasil.

${ }^{5}$ Professora-Adjunta do Departamento de Parasitologia e Microbiologia da UFPI -Teresina (PI) - Brasil.

${ }^{6}$ Professor-Doutor do Departamento de Química da UFPI -Teresina (PI) - Brasil.

Bolsista de Iniciação Científica - CNPQ e aluna do Curso de Graduação em Nutrição da UFPI - Teresina (PI) - Brasil.

${ }^{8}$ Bolsista de Iniciação Científica - CNPQ e aluna do

Curso de Graduação em Nutrição da UFPI - Teresina (PI)

- Brasil.

Endereço para correspondência: Fábio Martins Soares. Av. Frei Serafim 1.709 - Apto. 401 - Teresina (PI) CEP 64001-020

E-mail: fabiosoares@msn.com

Recebido para publicação em 03.03.2007

Última versão recebida em 25.04.2008

Aprovação em 29.05.2008

\section{RESUMO}

Objetivo: Determinar as concentrações plasmáticas e eritrocitárias de zinco em idosos portadores e não-portadores de catarata senil em um serviço oftalmológico especializado, em Teresina-Piauí. Métodos: Estudo quantitativo, transversal e controlado, realizado no Hospital de Olhos Francisco Vilar, Piauí, Brasil. Participaram 56 idosos (37 mulheres, 19 homens) sem condições associadas a modificações nos níveis de zinco ou aumento do risco de catarata. Escore $\geq$ II foi utilizado para definir a presença de catarata, de acordo com o Lens Opacities Classification System II. As concentrações de zinco foram determinadas por espectrometria de absorção atômica em chama. Análise estatística incluiu os testes $t$ de Student e qui-quadrado e 0,05 como nível de significância. Resultados: Catarata senil foi identificada em $58,9 \%$ dos participantes, predominando o tipo nuclear $(51,8 \%)$, seguido pelo cortical $(26,8 \%)$ e subcapsular posterior $(8,9 \%)$. Deficiência de zinco no plasma $(<70 \mu \mathrm{g} / \mathrm{dL})$ e no eritrócito $(<40 \mu \mathrm{g} / \mathrm{gHb})$ foi constatada em $49,1 \% \mathrm{e}$ $30,4 \%$ dos idosos, respectivamente. Não houve diferenças significativas entre portadores e não-portadores de catarata, independente do tipo, quanto às concentrações de zinco plasmático $(\mathrm{p}=0,165)$ ou eritrocitário $(\mathrm{p}=0,426)$. Conclusão: Deficiência de zinco no plasma ou eritrócito foi comum entre os idosos; porém, os dados indicam não haver diferenças significativas nos referidos parâmetros quanto à presença de catarata senil, independente do tipo.

Descritores: Zinco/sangue; Deficiência de zinco; Catarata; Estado nutricional; Idoso

\section{INTRODUÇÃ̃O}

A catarata é a principal causa de cegueira em todo o mundo, atingindo predominantemente os idosos ${ }^{(1)}$. O impacto econômico do seu tratamento - exclusivamente cirúrgico - é significativo ${ }^{(2)}$. Na medida em que a população de idosos aumenta, em termos absolutos e relativos, torna-se importante a realização de estudos que possam sugerir intervenções terapêuticas não-cirúrgicas ou preventivas ${ }^{(3)}$.

A etiopatogenia da catarata envolve a participação de eventos oxidativos mediados por radicais livres ${ }^{(4)}$. Admite-se que micronutrientes de propriedades antioxidantes, a exemplo do zinco, podem ter alguma função protetora - ainda não bem estabelecida - na gênese destes fenômenos ${ }^{(5)}$. 
A essencialidade do zinco aos organismos é conhecida desde o século XIX. ${ }^{\left({ }^{6}\right)}$ Integrante de numerosos processos bioquímicos e fisiológicos, o zinco é fundamental para a preservação da saúde e prevenção de doenças, incluindo patologias crônico-degenerativas, comuns nos idosos ${ }^{(7)}$. Entre estes últimos, tem sido descrita elevada prevalência de estados deficitários relativos ao mineral ${ }^{(8-9)}$.

Em comparação aos outros tecidos corporais, a concentração ocular de zinco é alta ${ }^{(10)}$. Sabe-se que o elemento compõe a estrutura de enzimas importantes para a fisiologia visual, como a superóxido-dismutase. A referida enzima parece ter atividade contra o estresse oxidativo e conseqüente cataratogênese ${ }^{(11)}$.

Ketola (1979), realizando trabalho experimental, conseguiu evitar o aparecimento de catarata, em Salmo gairdneri, com a administração de zinco ${ }^{(12)}$. Entretanto, o estudo $A R E D S$ não cofirmou o valor da suplementação do nutriente em relação à catarata senil ${ }^{(13)}$. Pesquisas têm associado alterações nas concentrações cristalinianas de zinco à ocorrência de catarata $^{(14-15)}$.

Trabalho anterior revelou que, entre portadores de catarata senil, a deficiência de zinco no plasma atingiu prevalência de $31 \%{ }^{(16)}$. Alguns autores, por sua vez, têm sugerido que a avaliação do elemento no eritrócito é mais apropriada para estudos de doenças crônicas ${ }^{(17)}$. Na literatura compulsada, entretanto, não se conseguiu identificar quaisquer trabalhos envolvendo a determinação do zinco eritrocitário em portadores de catarata senil.

Neste contexto, o objetivo do presente trabalho consistiu em determinar as concentrações plasmáticas e eritrocitárias de zinco em idosos portadores e não-portadores de catarata senil, num serviço oftalmológico especializado de Teresina-PI.

\section{MÉTODOS}

\section{Caracterização do estudo e sujeitos da pesquisa}

Estudo quantitativo, transversal controlado, desenvolvido no Hospital de Olhos Francisco Vilar (HOFV), em Teresina, Piauí, Brasil, no período de janeiro a setembro/2006, após aprovação do protocolo da pesquisa pelo Comitê de Ética em Pesquisa da Universidade Federal do Piauí, (parecer № 053/2005).

A amostra foi selecionada de forma não-aleatória, a partir da demanda espontânea do HOFV. Foram incluídos sujeitos com idade igual ou superior a 60 anos, independente de gênero ou raça, que apresentavam córnea transparente, seio camerular aberto (intermediário ou amplo) e boa dilatação pupilar após instilação de midriáticos. Foram excluídos indivíduos que apresentaram: antecedentes de trauma, cirurgia, procedimentos a laser oculares, uveíte e uso de mióticos ou corticosteróides tópicos. Excluíram-se, ainda, sujeitos mantidos em instituição de longa permanência, mentalmente incapacitados, portadores de doenças sistêmicas ou debilitantes, incluindo diabetes; usuários de drogas ou álcool, usuários de corticosteróides sistêmicos, diuréticos ou inibidores de anidrase sis- têmica e sujeitos em uso de suplementos nutricionais dietas especiais.

Quatrocentos e um idosos (158 homens e 243 mulheres) foram submetidos a exame oftalmológico completo; destes, selecionaram-se 56 participantes (19 homens e 37 mulheres), após o preenchimento dos critérios de elegibilidade e assinatura do termo de consentimento livre e esclarecido.

\section{Classificação das opacidades cristalinianas}

As opacidades cristalinianas foram classificadas de acordo com o Lens Opacification Classification System II (LOCS II) ${ }^{(18)}$, considerando a simplicidade e adequada reprodutibilidade intra-observador do referido método ${ }^{(19)}$.

A formação dos grupos foi realizada de acordo com critério adotado em trabalho anterior ${ }^{(20)}$. Em relação a cada tipo de catarata - nuclear $(\mathrm{N})$, cortical (C) ou subcapsular posterior (P) - foi considerado como portador o sujeito em que o escore de classificação fosse igual ou maior que "II", após avaliação binocular. Formaram-se, então, para cada tipo de catarata (N, $\mathrm{C}$ ou $\mathrm{P}$ ), de forma não-mutuamente exclusiva, grupo de portadores e grupo de não-portadores.

\section{Preparo das amostras e determinação do zinco}

Amostras sangüíneas ( $12 \mathrm{~mL}$ ) foram colhidas por meio de punção venosa, em tubos de ensaio desmineralizados contendo citrato de sódio a 30\%, entre 6 e 8 horas da manhã, após jejum mínimo de 10 horas. Separou-se o plasma do sangue total por centrifugação, em até três horas após a colheita. Empregou-se, ainda, técnica apropriada para a separação dos eritrócitos e remoção de contaminantes (plaquetas e leucó-

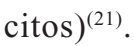

A determinação da concentração do zinco no plasma foi realizada por espectrometria de absorção atômica em chama ${ }^{(22)}$. Utilizou-se aparelho de espectrofotometria da marca VARIAN SS $220^{\mathrm{TM}}$. O equipamento foi calibrado com soluções aqüosas de glicerol a $3 \%$ e ácido nítrico a $1 \%$, preparadas por diluição de padrão de zinco Tritisol ${ }^{\circledR}$ (MERCK). Para verificar a exatidão das leituras, foi utilizado padrão certificado de Zinc-Atomic Spectroscopy Standard Solution Fluka 1,0000 g/L (Sigma Aldrich ${ }^{\circledR}$ ). Devido à perda de uma amostra durante processamento, o resultado foi obtido de 55 participantes. As concentrações foram fornecidas em microgramas de zinco/decilitros de plasma $(\mu \mathrm{g} / \mathrm{dL})$.

A determinação da concentração de zinco nos eritrócitos foi feita em duplicata, utilizando-se o mesmo equipamento e condições descritas para o plasma, modificando-se apenas os padrões de zinco, agora preparados em água MILLIQ ${ }^{\circledR}$ Water System. Determinou-se a hemoglobina $(\mathrm{Hb})$ através do método da cianometahemoglobina ${ }^{(23)}$. O resultado foi expresso em microgramas de zinco/gramas de hemoglobina ( $\mu \mathrm{g} / \mathrm{gHb})$.

Valores de zinco plasmático inferiores a $70 \mu \mathrm{g} / \mathrm{dL}$ foram considerados deficitários, segundo ponto-de-corte adotado por Gibson (1990) ${ }^{(17)}$. Concentrações de zinco no eritrócito foram consideradas deficitárias quando inferiores a $40 \mu \mathrm{g} / \mathrm{gHb}$, como propõem alguns autores ${ }^{(24)}$. 
As concentrações de zinco foram expressas como média \pm desvio-padrão. Após confirmada a distribuição normal dos dados, as médias dos grupos foram comparadas através do teste $t$ de Student. Adotou-se como nível de significância o valor de 5\%. O programa utilizado para a tabulação e realização dos testes estatísticos foi o SPSS, versão 13.0.

\section{RESULTADOS}

A média de idade dos participantes foi $67,14 \pm 5,49$ anos, variando de 60 a 80 anos. Aproximadamente dois terços $(66,1 \%)$ dos pesquisados eram do gênero feminino. Em relação à raça, metade $(50,0 \%)$ dos indivíduos eram pardos, ficando o restante distribuído entre pretos $(30,4 \%)$ e brancos $(19,6 \%)$.

A presença de catarata foi verificada em $58,9 \%$ dos idosos, sendo do tipo $\mathrm{N}$ em pouco mais da metade $(51,8 \%)$ dos sujeitos. A catarata $\mathrm{C}$ foi constatada em cerca de um quarto $(26,8 \%)$ dos participantes, enquanto cinco indivíduos $(8,9 \%)$ apresentaram catarata do tipo P. A média de idade dos portadores de catarata senil $(69,85 \pm 5,06$ anos) foi significativamente maior que a média dos não-portadores $(63,26 \pm 3,36$ anos $)(p<0,001)$.

A determinação do zinco plasmático revelou média de $70,99 \pm 18,63 \mu \mathrm{g} / \mathrm{dL}$ (IC 95\%: 65,95 - 76,02). Em relação ao zinco eritrocitário, a concentração média foi $44,33 \pm 9,15 \mu \mathrm{g} / \mathrm{gHb}$ (IC 95\%: 41,86 - 46,78). Os referidos parâmetros não evidenciaram diferenças estatisticamente significativas quanto à idade, gênero ou raça $(p>0,05)$.

A comparação das concentrações de zinco no plasma quanto à presença de catarata senil revelou que, independente do tipo, a diferença não alcançou significância estatística $(p=0,165)$. O mesmo comportamento foi observado quando se compararam as concentrações de zinco plasmático entre portadores e não-portadores de catarata $\mathrm{N}(\mathrm{p}=0,423), \mathrm{C}$ $(\mathrm{p}=0,853)$ ou $\mathrm{P}(\mathrm{p}=0,195)$, respectivamente (Tabela 1$)$.

Na tabela 1, verifica-se que não houve diferença significativa quanto às concentrações de zinco eritrocitário entre os idosos com catarata senil, independente do tipo, e os participantes sem a referida condição $(p=0,426)$. Também não existiu diferença significativa no referido parâmetro quanto à presença dos tipos classificados de catarata: $\mathrm{N}(\mathrm{p}=0,967), \mathrm{C}(\mathrm{p}=0,389)$ ou $\mathrm{P}$ $(\mathrm{p}=0,597)$.

A proporção de sujeitos com deficiência de zinco plasmático não foi estatisticamente diferente entre portadores e não-portadores de quaisquer tipos de catarata senil, como se percebe na tabela 2. Resultado semelhante foi obtido quando se analisou a proporção de idosos com deficiência do mineral no eritrócito quanto à presença de catarata senil, independente do tipo.

\section{DISCUSS ÃO}

Grande interesse tem havido na relação entre os nutrientes antioxidantes e o desenvolvimento da catarata senil, na medida em que mecanismos oxidativos têm sido implicados na cataratogênese $\mathrm{e}^{(4-5)}$.

\begin{tabular}{|c|c|c|}
\hline \multirow[t]{2}{*}{ Tipo de catarata* } & \multicolumn{2}{|c|}{$\begin{array}{l}\text { Concentração de zinco } \\
\text { (média } \pm \text { desvio-padrão) }\end{array}$} \\
\hline & $\begin{array}{c}\text { Plasma }(\mu g / d L) \\
(n)^{\star *}\end{array}$ & $\begin{array}{l}\text { Eritrócito }(\mu \mathrm{g} / \mathrm{gHb}) \\
(\mathrm{n})^{\star \star}\end{array}$ \\
\hline \multicolumn{3}{|l|}{ Nuclear } \\
\hline Presente & $\begin{array}{c}72,98 \pm 15,81 \\
(28)\end{array}$ & $\begin{array}{c}44,36 \pm 9,40 \\
(29)\end{array}$ \\
\hline Ausente & $\begin{array}{c}68,92 \pm 21,26 \\
(27)\end{array}$ & $\begin{array}{c}44,27 \pm 9,05 \\
(27)\end{array}$ \\
\hline \multicolumn{3}{|l|}{ Cortical } \\
\hline Presente & $\begin{array}{c}71,80 \pm 18,34 \\
(14)\end{array}$ & $\begin{array}{c}46,09 \pm 10,60 \\
(15)\end{array}$ \\
\hline Ausente & $\begin{array}{c}70,71 \pm 18,94 \\
(41)\end{array}$ & $\begin{array}{c}43,68 \pm 8,61 \\
(41)\end{array}$ \\
\hline \multicolumn{3}{|c|}{ Subcapsular posterior } \\
\hline Presente & $\begin{array}{c}82,67 \pm 23,78 \\
(4)\end{array}$ & $\begin{array}{c}42,23 \pm 9,32 \\
(5)\end{array}$ \\
\hline Ausente & $\begin{array}{c}70,07 \pm 18,14 \\
(51)\end{array}$ & $\begin{array}{c}44,53 \pm 9,20 \\
(51)\end{array}$ \\
\hline \multicolumn{3}{|l|}{ Qualquer tipo } \\
\hline Presente & $\begin{array}{c}73,96 \pm 16,51 \\
\text { (32) }\end{array}$ & $\begin{array}{c}45,15 \pm 9,10 \\
\text { (33) }\end{array}$ \\
\hline Ausente & $\begin{array}{c}66,86 \pm 20,90 \\
\text { (23) }\end{array}$ & $\begin{array}{c}43,15 \pm 9,30 \\
\text { (23) }\end{array}$ \\
\hline
\end{tabular}

\begin{tabular}{|c|c|c|c|c|}
\hline \multirow[t]{2}{*}{ Tipo de Catarata* } & \multicolumn{2}{|c|}{$\begin{array}{l}\text { Deficiência de } \\
\text { zinco no plasma }\end{array}$} & \multicolumn{2}{|c|}{$\begin{array}{c}\text { Deficiência de } \\
\text { zinco no eritrócito }\end{array}$} \\
\hline & $\%$ & $p$ & $\%$ & $p$ \\
\hline $\begin{array}{l}\text { Nuclear } \\
\text { Presente } \\
\text { Ausente }\end{array}$ & $\begin{array}{l}42,9 \\
55,6\end{array}$ & 0,251 & $\begin{array}{l}31,0 \\
29,6\end{array}$ & 0,570 \\
\hline $\begin{array}{l}\text { Cortical } \\
\text { Presente } \\
\text { Ausente }\end{array}$ & $\begin{array}{l}35,7 \\
53,7\end{array}$ & 0,198 & $\begin{array}{l}33,3 \\
29,3\end{array}$ & 0,506 \\
\hline $\begin{array}{l}\text { Subcapsular poster } \\
\text { Presente } \\
\text { Ausente }\end{array}$ & $\begin{array}{l}50,0 \\
49,0\end{array}$ & 0,681 & $\begin{array}{l}60,0 \\
27,5\end{array}$ & 0,158 \\
\hline $\begin{array}{l}\text { Qualquer tipo } \\
\text { Presente } \\
\text { Ausente }\end{array}$ & $\begin{array}{l}40,6 \\
60,9\end{array}$ & 0,113 & $\begin{array}{l}27,3 \\
34,8\end{array}$ & 0,378 \\
\hline
\end{tabular}

A concentração média do zinco plasmático encontrada entre os participantes do presente estudo foi superior à média encontrada em trabalho anterior realizado em idosos aparentemente saudáveis $(42,51 \pm 24,85 \mu \mathrm{g} / \mathrm{dL}$, nos homens, e 47,08 \pm $22,89 \mu \mathrm{g} / \mathrm{dL}$, nas mulheres ${ }^{(8)}$. Estes resultados também estão próximos aos achados de Cordeiro e Artacho et al. respectivamente $68,60 \pm 22,89$ e $68,00 \pm 12,09 \mu \mathrm{g} / \mathrm{dL}^{(25-26)}$. Todavia, outros 
autores têm encontrado concentrações de zinco plasmático mais elevadas, variando de 84,36 a $113,30 \mu \mathrm{g} / \mathrm{dL}$, em idosos ${ }^{(27-28)}$.

Entre os portadores de catarata senil, a média encontrada para o zinco plasmático situou-se próximas dos valores revelados no estudo AREDS ${ }^{(29)}$.

Entretanto, outros pesquisadores verificaram concentrações maiores, em portadores de catarata ${ }^{(14-15,30)}$.

$\mathrm{Na}$ presente investigação, comparando-se as concentrações de zinco plasmático entre portadores e não-portadores de catarata senil, não se verificou diferença estatisticamente significativa. Neste ponto, a literatura é controvertida, pois, enquanto alguns autores encontraram aumento de zinco plasmático entre portadores de catarata senil ${ }^{(31-32)}$, outros constataram diminuição das concentrações séricas de zinco em idosos com catarata ${ }^{(33)}$. As diferenças de resultados entre os estudos podem ser atribuídas às características dos indivíduos avaliados e às diferenças na ingestão de zinco ${ }^{(25)}$. Outra hipótese seria a possível relação do zinco com o desenvolvimento ou grau de maturidade da catarata ${ }^{(33)}$.

Categorizando os tipos de catarata senil (N, C e P), este trabalho não encontrou diferenças significativas nas concentrações de zinco no plasma entre portadores e não-portadores de cada tipo, respectivamente (Tabela 1). Neste contexto, a literatura sobre níveis de zinco plasmático em relação aos tipos de catarata senil é escassa. Estudo prévio, em que se avaliaram 20 pacientes, encontrou concentrações de zinco normais, exceto nos portadores de catarata avançada $(n=3)$ e catarata complicada $(n=1)$, que revelaram concentrações elevadas ${ }^{(34)}$. Em outra pesquisa, verificou-se aumento não-significativo do risco de catarata subcapsular posterior com a elevação do zinco plasmático $^{(35)}$. De forma semelhante, esta pesquisa constatou concentração média de zinco plasmático superior nos portadores de catarata subcapsular posterior, sem ter havido, contudo, diferença estatisticamente significativa.

No presente estudo, quase a metade dos idosos apresentaram concentrações deficitárias de zinco plasmático. Não houve diferença significativa nos valores de zinco plasmático entre portadores e não portadores de catarata senil. Em trabalho anterior, entretanto, encontrou-se prevalência de 59,5\% de deficiência de zinco no plasma entre idosos hospitalizados $(n=202)$ por causas diversas, e de $31 \%$, entre portadores de catarata senil $(\mathrm{n}=21)^{(16)}$.

$\mathrm{Na}$ avaliação do estado nutricional relativo ao zinco, poucos pesquisadores têm usado a determinação do mineral no eritrócito, em decorrência das dificuldades de análise, que envolvem desde a etapa de separação dos componentes celulares aos problemas relacionados com interferência de matriz ${ }^{(17)}$.

A concentração média de zinco no eritrócito encontrada no presente estudo situa-se dentro da faixa considerada normal para o adulto $(42,2 \pm 5,6 \mu \mathrm{g} / \mathrm{gHb})$, segundo valores de referência da literatura mundial ${ }^{(17)}$, e acima dos valores médios encontrados por outros autores $(35,26$ a $38,75 \mu \mathrm{g} / \mathrm{gHb})$, em $\operatorname{idosos}^{(25,36)}$.

$\mathrm{Na}$ literatura consultada, não se encontraram trabalhos que envolvessem a determinação do zinco no eritrócito em portadores de catarata, apesar do referido indicador ser teoricamente apropriado para estudos de doenças crônicas ${ }^{(17)}$. Nesta pesquisa, não foram encontradas diferenças entre portadores e não-portadores de quaisquer tipos de catarata senil (N, C ou P) quanto ao citado parâmetro (Tabela 2).

Entretanto, o real valor da determinação do zinco no eritrócito não está claramente definido ${ }^{(6)}$. Acredita-se que estes resultados poderão servir para comparações futuras e, conseqüentemente, contribuir para se esclarecer o comportamento do zinco nos portadores de catarata senil.

\section{CONCLUSÃO}

Os resultados sugerem não haver diferenças nas concentrações plasmáticas ou eritrocitárias de zinco quanto à presença de catarata senil, independente do tipo (N, C ou P). Dentre os pacientes investigados, parcela significativa dos idosos apresentam concentrações deficitárias do elemento no plasma ou eritrócito, independente da presença ou ausência de catarata.

\section{AGRADECIMENTO}

Ao Dr. Francisco das Chagas Vilar, diretor clínico do HOFV, por ter disponibilizado gentilmente as instalações e equipamentos da referida instituição para a realização deste estudo.

\section{ABSTRACT}

Purpose: To determine plasma and erythrocyte zinc concentrations in elderly with and without senile cataract in a tertiary eye care center at Teresina-Piauí. Methods: A quantitative, transversal and controlled study was developed at the Hospital de Olhos Francisco Vilar, Piauí, Brasil. Fifty-six elderly subjects (37 females, 19 males) with no known conditions that modify zinc blood levels or increase risk of cataract were included. A score $\geq$ II was used to define cataract, according to Lens Opacities Classification System II. Plasma and erythrocyte zinc concentrations were determined by flame atomic absorption spectrometry. Statistical tests included Student's $t$ and chi-square tests, with a probability level of 0.05 as significant. Results: Senile cataract was present in $58.9 \%$ of the subjects. The most common type was nuclear $(51.8 \%)$, followed by cortical $(26.8 \%)$ and posterior subcapsular $(8.9 \%)$. Zinc deficiencies in plasma $(<70 \mu \mathrm{g} / \mathrm{dL})$ and erythrocyte $(<40 \mu \mathrm{g} / \mathrm{gHb})$ were found in $49.1 \%$ and $30.4 \%$ of participants, respectively. There were no significant differences between elderly with or without cataract, regardless of type, in relation to plasma $(\mathrm{p}=0.165)$ or erythrocyte $(\mathrm{p}=0.426)$ zinc concentrations. Conclusion: Zinc deficiency in plasma or erythrocyte were common among the elderly. However, the data suggest that no significant differences exist between elderly with or without senile cataract, regardless of type, in relation to the referred parameters of zinc evaluation. 
Keywords: Zinc/blood; Zinc deficiency; Cataract; Nutritional status; Aged

\section{REFERÊNCIAS}

1. Resnikoff S, Pascolini D, Etya'ale D, Kocur I, Pararajasegaram R, Pokharel GP, et al. Global data on visual impairment in the year 2002. Bull World Health Organ. 2004;82(11):844-51.

2. Ellwein LB, Urato C. Use of eye care and associated charges among the Medicare population: 1991-1998. Arch Ophthalmol. 2002;120(6):804-11.

3. Tucker KL, Buranapin S. Nutrition and aging in developing countries. J Nutr. 2001;131(9):2417S-23S

4. Spector A. Oxidative stress-induced cataract: mechanism of action. FASEB J. 1995;9(12):1173-82.

5. Meyer $\mathrm{CH}$, Sekundo W. Nutritional supplementation to prevent cataract formation. Dev Ophthalmol. 2005;38:103-19.

6. Yuyama LK, Yonekura L, Aguiar JPL, Rodrigues ML, Cozzolino SM. Zinco. In: Cozzolino SM, editor. Biodisponibilidade de nutrientes. São Paulo: Manole; 2005. p. 513-38

7. Tudor R, Zalewski PD, Ratnaike RN. Zinc in health and chronic disease. J Nutr Health Aging. 2005;9(1):45-51.

8. Cesar T, Wada S, Borges R. Zinco plasmático e estado nutricional em idosos. Rev Nutr. 2005;18(3):357-65.

9. Pepersack T, Rotsaert P, Benoit F, Willems D, Fuss M, Bourdoux P, et al Prevalence of zinc deficiency and its clinical relevance among hospitalised elderly. Arch Gerontol Geriatr. 2001;33(3):243-53.

10. Karcioglu ZA. Zinc in the eye. Surv Ophthalmol. 1982;27(2):114-22.

11. Behndig A, Karlsson K, Reaume AG, Sentman ML, Marklund SL. In vitro photochemical cataract in mice lacking copper-zinc superoxide dismutase. Free Radic Biol Med. 2001;31(6):738-44.

12. Ketola HG. Influence of dietary zinc on cataracts in rainbow trout (Salmo gairdneri). J Nutr. 1979;109(6):965-9.

13. Age-Related Eye Disease Study Research Group. A randomized, placebocontrolled, clinical trial of high-dose supplementation with vitamins $\mathrm{C}$ and $\mathrm{E}$ and beta carotene for age-related cataract and vision loss: AREDS report no. 9. Arch Ophthalmol. 2001;119(10):1439-52.

14. Aydin E, Cumurcu T, Ozugurlu F, Ozyurt H, Sahinoglu S, Mendil D, et al. Levels of iron, zinc, and copper in aqueous humor, lens, and serum in nondiabetic and diabetic patients: their relation to cataract. Biol Trace Elem Res. 2005;108(1-3):33-41.

15. Gunduz G, Gunduz F, Yucel I, Senturk UK. Levels of zinc and magnesium in senile and diabetic senile cataractous lenses. Biol Trace Elem Res. 2003;95(2):107-12.

16. Vannuchi H, Cunha DF, Bernardes MM. Avaliação dos níveis séricos das vitaminas A, E, C e B2, de carotenódes e zinco, em idosos hospitalizados. Rev Saúde Pública. 1994;28(2):121-6.

17. Gibson RS. Assesment of trace-element status. In: Gibson RS. editor. Principles nutritional assesment. New York: Oxford University Press; 1990. p.542-53.

18. Chylack LT Jr, Leske MC, McCarthy D, Khu P, Kashiwagi T, Sperduto R. Lens opacities classification system II (LOCS II). Arch Ophthalmol. 1989; 107(7):9917. Comment in: Arch Ophthalmol. 1990;108(9):1209-10.

19. Maraini G, Pasquini P, Tomba MC, Bonacini M, Stazi MA, Rosmini F, et al. An independent evaluation of the Lens Opacities Classification System II (LOCS II) The Italian-American Cataract Study Group. Ophthalmology. 1989;96(5):611-5.

20. Hennis A, Wu SY, Nemesure B, Leske MC; Barbados Eye Studies Group. Risk factors for incident cortical and posterior subcapsular lens opacities in the Barbados Eye Studies. Arch Ophthalmol. 2004;122(4):525-30.

21. Whitehouse RC, Prasad AS, Rabbani PI, Cossack ZT. Zinc in plasma, neutrophils, lymphocytes, and erythrocytes as determined by flameless atomic absorption spectrophotometry. Clin Chem. 1982;28(3):475-80.

22. Rodriguez MP, Narizano A, Cid A. A simples method for the determination of zinc human plasma levels by flame atomic absorption spectrophotometry. A Spectr. 1989;10(2):68-70.

23. Van Assendelft OW. The measure of hemoglobin. In: Izack G, Lewis SM. editors. Modern concept in Hematology. New York: Academy Press; 1972, p.14-25.

24. Guthrie HA, Picciano MF. Human nutrition. New York: Mosby; 1994.: Chapter 4: Nutrient minerals. p.351-7.

25. Cordeiro MBC. Adequação alimentar e avaliação do estado nutricional em relação ao zinco em grupo de idosos institucionalizados [tese]. São Paulo: Universidade de São Paulo; 1994.

26. Artacho R, Ruiz-Lopez MD, Gamez C, Puerta A, Lopez MC. Serum concentration and dietary intake of $\mathrm{Zn}$ in healthy institutionalized elderly subjects. Sci Total Environ. 1997;205(2-3):159-65.

27. Andriollo-Sanchez M, Hininger-Favier I, Meunier N, Toti E, Zaccaria M, Brandolini-Bunlon M, et al. Zinc intake and status in middle-aged and older European subjects: the ZENITH study. Eur J Clin Nutr. 2005;59(Suppl 2):S37-41.

28. Hotz C, Peerson JM, Brown KH. Suggested lower cutoffs of serum zinc concentrations for assessing zinc status: reanalysis of the second National Health and Nutrition Examination Survey data (1976-1980). Am J Clin Nutr. 2003;78(4): 756-64.

29. Age-Related Eye Disease Study Research Group. The effect of five-year zinc supplementation on serum zinc, serum cholesterol and hematocrit in persons randomly assigned to treatment group in the age-related eye disease study: AREDS Report no. 7. J Nutr. 2002;132(4):697-702.

30. Anderson AR, Kastl P, Karcioglu ZA. Comparison of aqueous humor and serum zinc levels in humans. Br J Ophthalmol. 1987;71(3):212-4.

31. Sethi A, Nath K, Ahmad N, Gupta KP, Chandra O. A study of the trace elements in human cataractous lenses and sera. Indian J Ophthalmol. 1987;35(5-6):201-3

32. Yang $\mathrm{W}, \mathrm{Yu} \mathrm{W}, \mathrm{Li} \mathrm{Z}$. [The study on superoxide dismutase and trace element in patients with senile cataract]. Yan Ke Xue Bao. 2000;16(4):246-8, 234. [Chinese]

33. Chen CZ. [Analysis of 7 elements in the serum and lens of senile cataract patients]. Zhonghua Yan Ke Za Zhi. 1992;28(6):355-7. [Chinese]

34. Krishna PG, Rao KS, Devi OB, Naidu GR. Analysis of samples of human serum with cataracts for zinc and iron by flame atomic absorption spectrometry. Indian J Environ Health. 2003;45(3):189-94.

35. Jacques PF, Hartz SC, Chylack LT Jr, McGandy RB, Sadowski JA. Nutritional status in persons with and without senile cataract: blood vitamin and mineral levels. Am J Clin Nutr. 1988;48(1):152-8.

36. Prasad AS, Fitzgerald JT, Hess JW, Kaplan J, Pelen F, Dardenne M. Zinc deficiency in elderly patients. Nutrition. 1993;9(3):218-24.

\section{Nos artigos enviados para publicação, o nome} dos autores e suas afiliações devem estar completos. Isso facilitará a indexação e os links com as bases de dados e o CV Lates. 